\title{
EFFECTS OF IMPLEMENTING MODULAR CONTAINER STRUCTURE TOWARDS THE ROOM AND CORRIDOR QUALITY IN CHARA HOTEL
}

\author{
${ }^{1}$ Nathania Nadia. ${ }^{2}$ Laurentia Carissa, S.T., M.T. \\ ${ }^{1}$ Student in the Bachelor's (S-1) Study Program in Architecture \\ at Parahyangan Catholic University \\ ${ }^{2}$ Senior lecturer in the Bachelor's (S-1) Study Program in Architecture \\ at Parahyangan Catholic University
}

\begin{abstract}
Containers have a lifetime, so afterwards abandoned. The use of used containers as buildings has grown and become popular in some countries. Containers have fixed length, width and height. The use of containers as a hotel function requires adjustment of size and material. This research will analyze how far the fixed container structure is used in the Chara Hotel, adapters of fixed containers with the space requirements in them and the effect of container material on human psychology.

Research is reviewed in quantitative (size) and qualitative (psychological effects). The research will be done by looking how far the container structure is used in the building. Analysis of how closely the relationship between the structure of the container and the rigid frame with the bedroom and corridor architecture is in terms of room size and space quality.

The size of the contianer dimension can be put to good use as a function of the bedroom. Structural containers and rigid frame structures is a frame structures and architectural structures. The length and height of the corridor are good, the width of the corridor is less wide. The function of the space of the container structure and the rigid frame to space is good because the structure does not impede function and circulation.
\end{abstract}

Key Words: container structure, rigid frame structure, space quantity, space quality

\section{PENGARUH PENGGUNAAN MODUL KONTAINER TERHADAP KUALITAS RUANG KAMAR DAN KORIDOR HOTEL CHARA}

\author{
${ }^{1}$ Nathania Nadia. ${ }^{2}$ Laurentia Carissa, S.T., M.T. \\ ${ }^{1}$ Mahasiswa S1 Program Studi Arsitektur Universitas Katolik Parahyangan \\ 2 Dosen Pembimbing S1 Program Studi Arsitektur Universitas Katolik Parahyangan
}

\begin{abstract}
Abstrak- Kontainer memiliki masa pakai, sehingga setelahnya terbengkalai. Penggunaan kontainer bekas sebagai bangunan telah tumbuh dan popular di beberapa negara. Kontainer memiliki ukuran panjang, lebar, dan tinggi yang tetap. Pemakaian kontainer sebagai fungsi hotel memerlukan penyesuaian ukuran dan material. Penelitian ini akan menganalisis seberapa jauh struktur tetap kontainer dipakai dalam Hotel Chara, penyesuaikan kontainer tetap dengan kebutuhan ruang di dalamnya dan pengaruh material kontainer terhadap psikologi manusia.

Penelitian ditinjau secara kuantitatif (ukuran) dan kualitatif (efek psikologis). Penelitian akan dilakukan dengan melihat seberapa jauh struktur kontainer dipakai dalam bangunan. Analisis seberapa dekat hubungan struktur kontainer dan rangka kaku dengan arsitektur kamar tidur dan koridor yaitu dari sisi besaran ruang dan kualitas ruang.
\end{abstract}

${ }^{1}$ Corresponding Author: nianadia22@yahoo.com 
Ukuran dimensi kontianer dapat dimanfaatkan dengan baik sebagai fungsi kamar tidur. Struktur kontainer dan struktur rangka kaku termasuk struktur bingkai dan struktur sebagai arsitektur. Ukuran panjang dan tinggi koridor baik, ukuran lebar koridor kurang lebar. Fungsi ruang struktur kontainer dan rangka kaku terhadap ruang adalah baik karena struktur tidak menghalangi fungsi dan sirkulasi.

Kata Kunci: struktur kontainer, struktur rangka kaku, besaran ruang, kualitas ruang

\section{PENDAHULUAN}

Kontainer merupakan kotak atau peti yang memiliki syarat teknis ISO (International Organization for Standardization) yang memiliki fungsi untuk mengangkut barang yang bisa digunakan oleh berbagai moda jalan antara lain truk kontainer, kereta api, kapal kontainer laut dan pesawat terbang. Namun kontainer bekas terbengkalai di tempat seperti pelabuhan, karena biaya yang tinggi untuk mengembalikan ke tempat asal. Maka muncul pemikiran bahwa kontainer bekas dapat digunakan sebagai sesuatu yang bermanfaat, salah satunya adalah sebagai bangunan. Tahun 2000 ide pemakaian kontainer diaplikasikan pada proyek Container City I di London oleh perusahaan Urban Space dan pemakaiannya terus berkembang di beberapa negara termasuk Indonesia.

Kontainer memiliki ukuran panjang, lebar, dan tinggi yang tetap sesuai standar yang berlaku. Dengan ukuran dan fungsi tetap, maka dalam penelitian ini akan dianalisis mengenai struktur kontainer dimanfaatkan pada bangunan, hubungan struktur kontainer dan rangka kaku dengan besaran ruang dan hubungan struktur kontainer dan rangka kaku dengan kualitas ruang.

Hotel Chara merupakan hotel di Bandung yang terletak di Jalan Gatot Subroto no. 31. Dibangun di atas bangunan tiga lantai yang memiliki fungsi spa keluarga yaitu AMAIA. Isu desain awal adalah bangunan memerlukan sistem konstruksi bangunan yang ringan serta fleksibel yang mampu beradaptasi dengan bangunan yang telah ada. Struktur kontainer dipilih menjadi struktur yang digunakan dengan pertimbangan cepat dan ringan dalam pengerjaan.

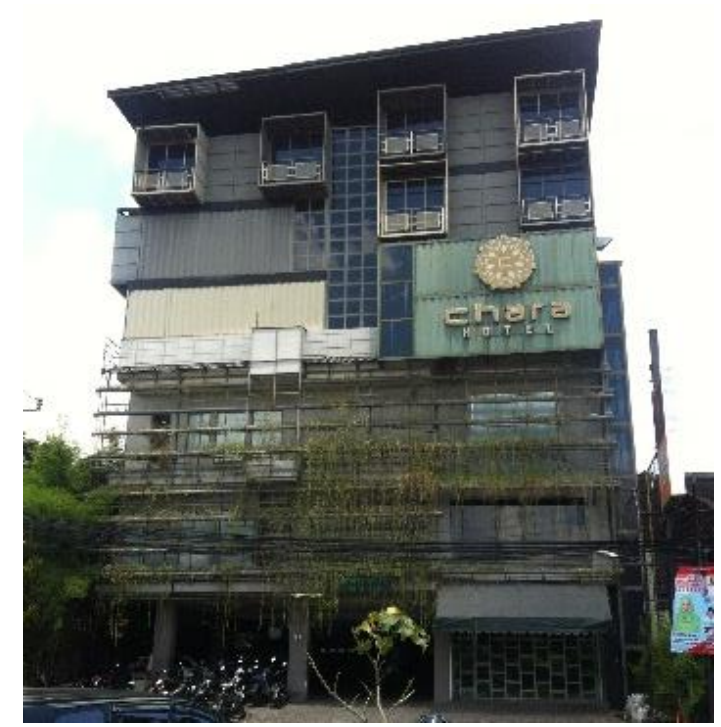

Figur 1. Hotel Chara 


\section{KAJIAN TEORI}

Teori berikut akan membahas mengenai struktur, ruang dan hubungan struktur dengan arsitektur (ruang).

\subsection{STRUKTUR KONTAINER DAN RANGKA KAKU}

Struktur yang akan dibahas adalah struktur kontainer dan rangka kaku yang digunakan dalam bangunan ini. Struktur kontainer dipakai dalam unit kamar hotel, sedangkan struktur rangka kaku dipakai pada koridor. Kedua struktur saling terkait satu dengan yang lain.

\subsubsection{STRUKTUR KONTAINER}

Standar awal yang dikeluarkan ISO adalah panjang 10 feet, 20 feet, 30 feet, 40 feet, lebar 8 feet dan tinggi 8 feet dan 8,6 feet. Mayoritas kontainer di seluruh dunia saat ini mematuhi standar ISO. Permintaan akan kontainer yang lebih besar terus berkembang, sehinggi ISO mengeluarkan standar kontainer dengan panjang 45 feet dan 48 feet, lebar 8,6 feet dan tinggi 9,6 feet ${ }^{2}$

Terdapat beberapa jenis kontainer, namun jenis yang umum dipakai dalam bangunan adalah General Purpose Container dengan elemen struktur sebagai berikut: empat corner casting, dua bottom side rail, dua top side rails, dua bottom cross members, front top end rail dan a door header. Kontainer yang dipakai adalah jenis High Cube 20 feet dengan ukuran 6 x 2,4 x 2x9 meter.

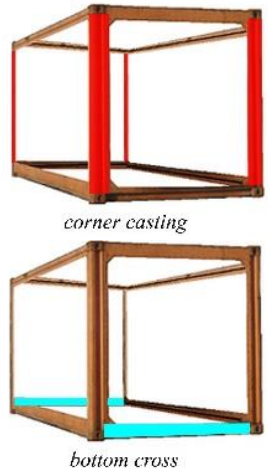

Figur 2. Elemen struktur basic container frame

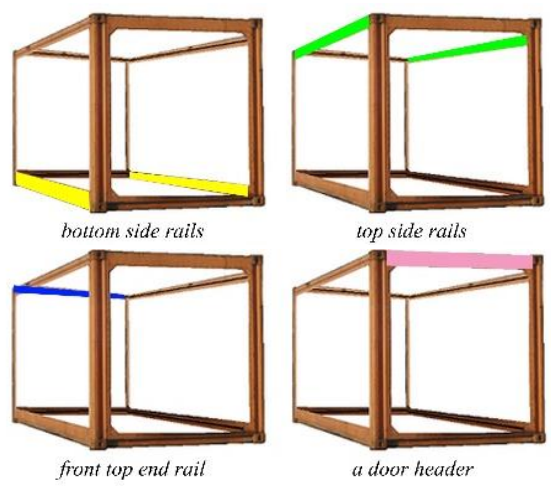

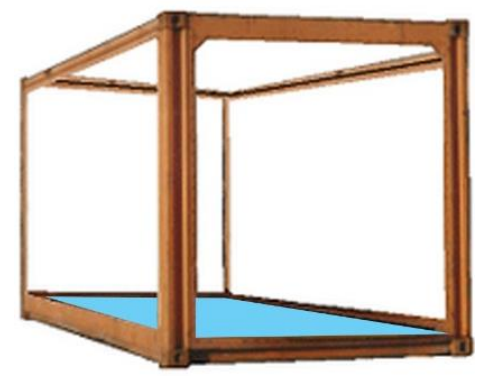

Figur 3. Bottom cross members

Pada kontainer, kekuatan beban aksial disalurkan melalui rangka kontainer, sedangkan panel dinding dan atap hanya menerima sangat sedikit beban. Pemotongan maupun pembuatan lubang pada dinding dan atap tidak mempengaruhi penyaluran beban dan kekuatan kontainer. Maka struktur kontainer masuk kedalam jenis rangka (skeleton type).

\subsubsection{STRUKTUR RANGKA KAKU}

Struktur rangka kaku (Rigid Frame) merupakan struktur yang terbentuk atas elemen-elemen linear, biasanya balok dan kolom serta saling menghubungkan pada ujung-ujungnya oleh titik hubung (joint) sehingga dapat mencegah rotasi antara elemen struktur yang saling berhubungan ${ }^{3}$. Struktur rangka kaku digunakan pada koridor.

\footnotetext{
2 The German Insurance Association (GDV e.V) “Container Handbook” Germany 2010

${ }^{3}$ Daniel L. Schodek.1999.Struktur.Jakarta : Penerbit Erlangga
} 


\subsection{RUANG}

Ruang yang akan dianalisis terbagi dalam dua bagian yaitu besaran ruang dan kualitas ruang. Besaran ruang berhubungan dengan yang bisa terukur; lebar, panjang, tinggi, luas ruangan. Besaran ruang yang akan dibahas adalah proporsi dan fungsi ruang. Kualitas ruang dilihat dari yang terdapat dalam ruangan dan mempengaruhi psikologis pengguna di dalamnya. Kualitas ruang yang akan dibahas adalah warna, pola dan tekstur.

\subsubsection{BESARAN RUANG}

Analisis besaran ruang akan dilihat dari sisi dimensi dan fungsi ruang. Dimensi mencakup proporsi ergonometri manusia sesuai standar kenyaman gerak manusia pada ruangan kamar tidur dan koridor. Fungsi ruang akan ditinjau mengenai struktur memberi pengaruh kepada pembentukan ruang dalam.

\subsubsection{KUALITAS RUANG}

Kualitas ruang dirasakan melalui panca indera, sehingga lingkungan fisik ruang sangat mempengaruhi kualitas ruang. Sensor organ dan pengalaman masa lalu dapat membuat manusia memiliki perasaan kuat terhadap suatu ruang dan kualitas ruang adalah peragaan atau kinesthesia, sentuhan dan penglihatan (Yi Fu Tuan, 1997). DK. Ching (1996) mengatakan bahwa ruang arsitektur dipengaruhi oleh: permukaan sisi-sisi: warna, pola dan tekstur.

Warna dapat membangkitkan perasaan melalui indera penglihatan (Hendraningsih, 1985). Warna pada elemen langit-langit, dinding maupun lantai akan memberi kualitas ruang yang berbeda. Menurut J. Pamudji Suptandar, menjelaskan bahan yang dipakai akan mempengaruhi pembentukan suasana ruang. Tekstur merupakan kualitas spasifik permulaan yang dihasilkan oleh struktur tri matra (Ching, 1996).

\subsection{HUBUNGAN STRUKTUR DENGAN ARSITEKTUR}

Menurut teori Charleson (2005) dan Macdonald (2001) hubungan struktur dengan arsitektur (kualitas ruang) akan dilihat seberapa baik hubungannya, jika struktur diubah dan menghasilkan kualitas ruang yang cocok dengan fungsi maka hubungannya baik begitu pula sebaliknya.

\section{METODA PENELITIAN}

Penelitian menggunakan metode kuantitatif dan kualitatif dengan survei lapangan, studi literatur dan wawancara. Penelitian dibatasi pada ruang kamar dan koridor karena kedua ruang tersebut berhubungan langsung dengan struktur kontainer.

\section{ANALISA}

Struktur kontainer dipakai pada unit kamar Hotel Chara, struktur rangka kaku dipakai pada koridor. Fasad hotel memperlihatkan dengan jelas struktur kontainer, pada interior pula dapat terlihat dinding seng gelombang kontainer.

Pembahasan akan dilakukan secara bertahap dari bagaimana struktur digunakan dalam bangunan hotel, kemudian akan dianalisis bagaimana struktur memengaruhi pembagian ruang 
dalam. Kualitas ruang juga akan dianalisis, bagaimana perubahan kualitas ruang akibat perubahan material.

\subsection{STRUKTUR KONTAINER DAN STRUKTUR RANGKA KAKU}

Pemakaian struktur kontainer pada bangunan Hotel Chara terdapat pada ruang dalam kamar tidur dan koridor. Oleh karena itu, pembahasan dibatasi pada struktur kontainer pada kamar dan sturktur rangka kaku pada koridor.

\subsubsection{STRUKTUR KONTAINER}

Posisi susunan kontainer disusun secara rapi dari lantai 4, 5, dan 6, namun terdapat tiga kontainer paling atas yang ditempatkan secara melintang 90 derajat. Jika dilihat dari samping, terdapat perbedaan posisi kontainer pada masing-masing lantai. Pada kontainer lantai 4 terdapat penambahan panjang kontainer dengan tujuan memperluas kamar. Kontainer lantai 5 dan 6 terdapat penambahan panjang kontainer sebagai fungsi balkon.

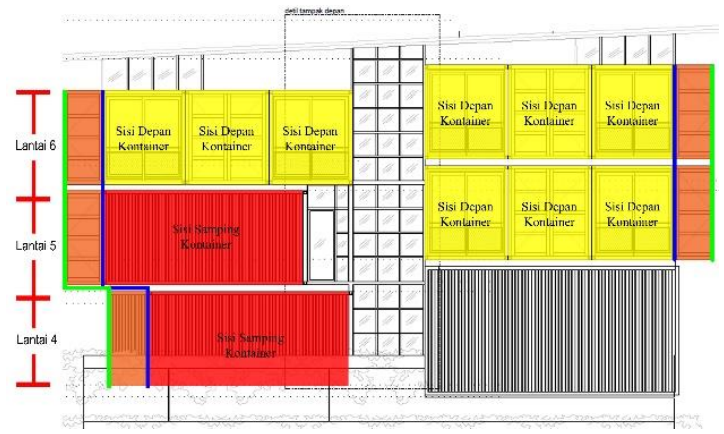

Figur 4. Perbedaan posisi kontainer

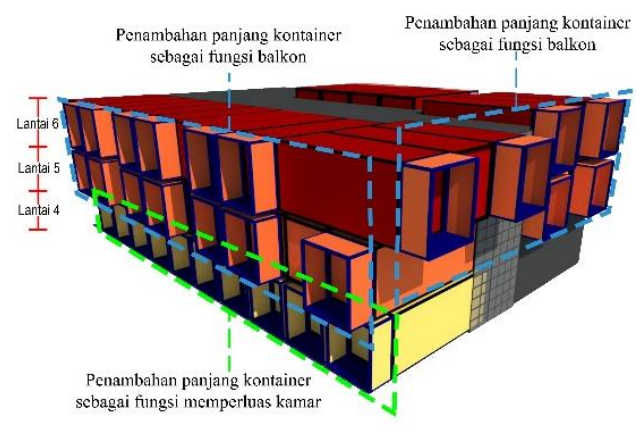

Figur 5. Penambahan panjang kontainer

Terdapat 4 unit kamar yaitu standar twin, deluxe king, superior suite dan junior suite. Berikut ini tabel ukuran kamar dengan berpacu pada ukuran kontainer.

Tabel 1. ukuran kamar

\begin{tabular}{|l|l|l|l|}
\hline Unit kamar & Panjang & Lebar & Tinggi \\
\hline Standar twin & 1 panjang kontainer & 1,5 lebar kontainer & 1 tinggi kontainer \\
\hline Deluxe King & $\begin{array}{l}\text { 1 panjang kontainer + 1,5 } \\
\text { meter }\end{array}$ & 1,5 lebar kontainer & 1 tinggi kontainer \\
\hline Superior suite & 1 panjang kontainer & 1,5 lebar kontainer & 1 tinggi kontainer \\
\hline Junior suite & 1 panjang kontainer & 2 lebar kontainer & 1 tinggi kontainer \\
\hline
\end{tabular}

Ukuran lebar kontainer yang dipakai untuk kamar, ada yang dua kontainer, ada yang 1,5 lebar kontainer. Dengan begitu dapat diketahui bahwa ada pengurangan dinding kontainer bagian tengah. Struktur kontainer masuk ke dalam kategori skeleton type sehingga dinding dan atap hanya sangat sedikit menyalurkan beban. Sehingga dalam bangunan ini, pengurangan dinding tidak akan memperlemah struktur. 

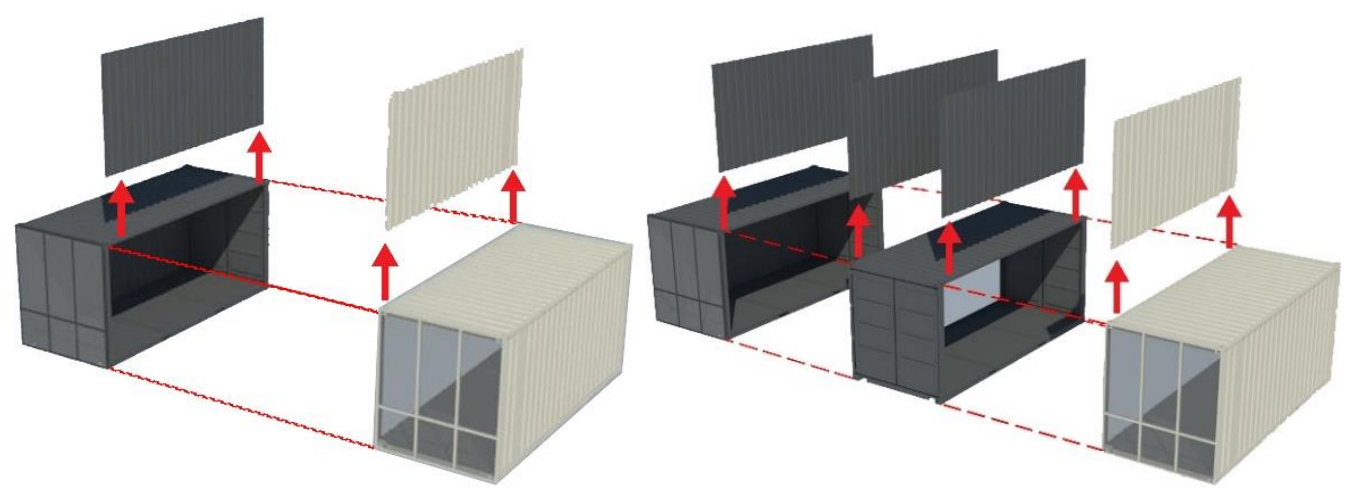

Figur 6. Dua dan tiga kontainer dengan pengurangan dinding kontainer

Dinding kontainer bagian depan diganti fungsi menjadi jendela dan dinding kontainer bagian belakang ditambah fungsi pintu kayu. Sehingga jika dikelompokkan, terdapat tiga tipe kontainer dengan pengurangan dinding samping dan perubahan fungsi dinding depan dan belakang. Tipe kontainer 1 menghilangkan satu dinding kiri, mengganti fungsi dinding depan sebagai kaca dan dinding belakang sebagai pintu. Tipe kontainer 2 menghilangkan satu dinding kanan, mengganti fungsi dinding depan sebagai kaca dan dinding belakang sebagai pintu. Tipe kontainer 3 menghilangkan kedua dinding kanan dan kiri, dinding depan dan belakang tidak diganti.

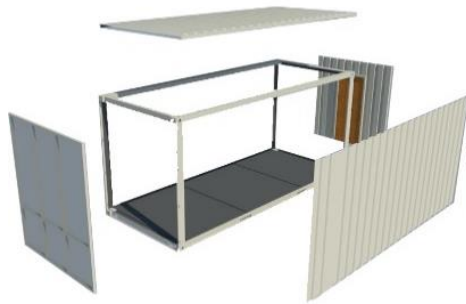

TIPE KONTAINER I

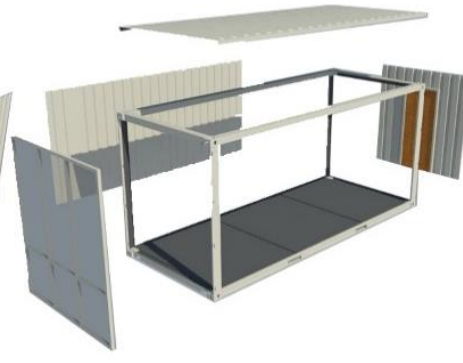

TIPE KONTAINER II

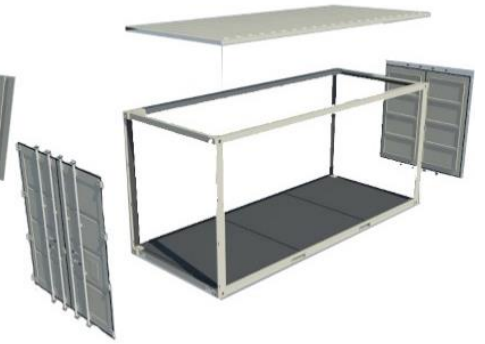

TIPE KONTAINER III

Figur 7. Tiga tipe kontainer

Terdapat baja IWF dibawah semua kontainer, dibawah seluruh kontainer lantai 6 dan lantai 5 terdapat IWF 200 sedangkan dibawah kontainer lantai 4 terdapat IWF 250.

Proses pembuatan kontainer lantai 4, 5, 6

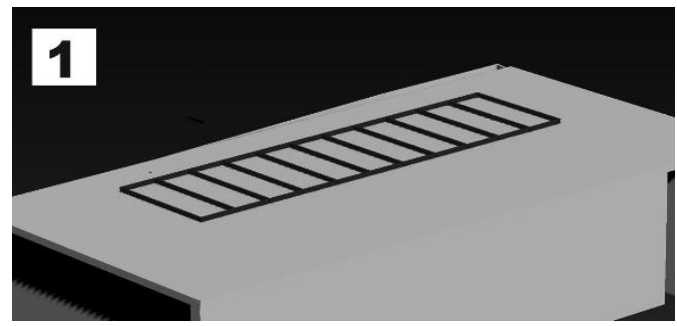

Figur 8. Baja IWF 250

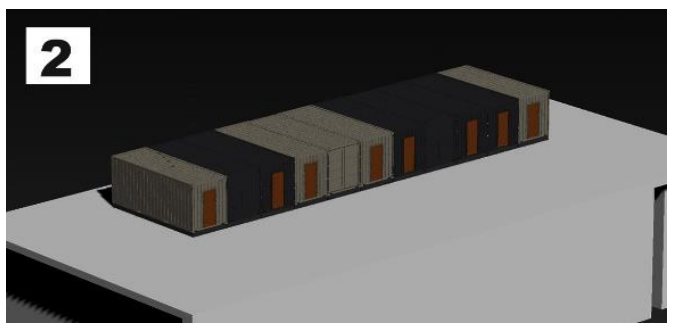

Figur 9. Susunan kontainer lantai 4 


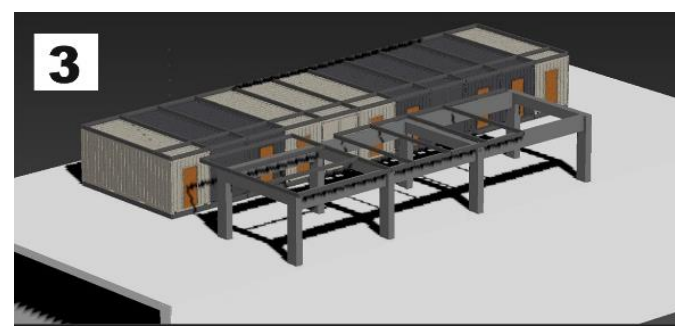

Figur 10. Baja IWF 200 lantai 5

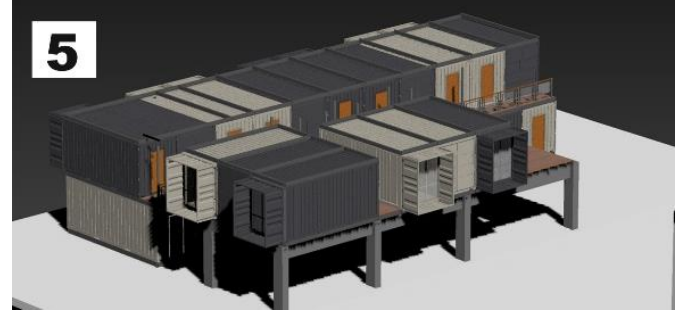

Figur 13. Baja IWF 200 lantai 6

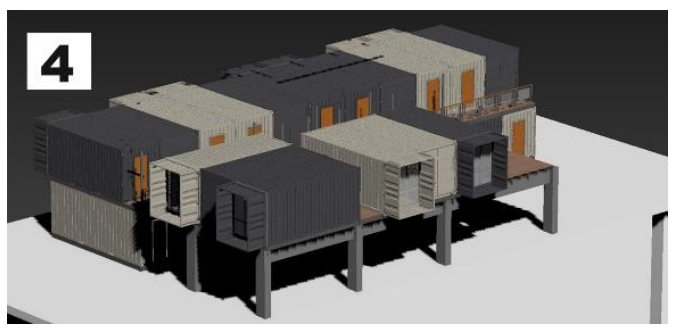

Figur 11. Susunan kontainer lantai 5

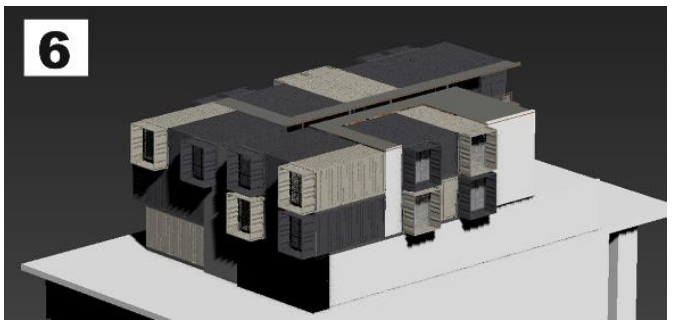

Figur 13. Susunan kontainer lantai 6

Baja IWF yang berada di bawah kontainer memiliki fungsi yaitu sebagai balok karena terdapat posisi kontainer yang tidak tepat berada di atas kontainer lainnya. Ketidaktepatan posisi kontainer memiliki tujuan lain selain variasi visual yaitu untuk memberi ruang bagi fungsi koridor. Sehingga baja IWF memiliki fungsi lain yaitu mengikat struktur rangka kaku yang merupakan struktur utama koridor.

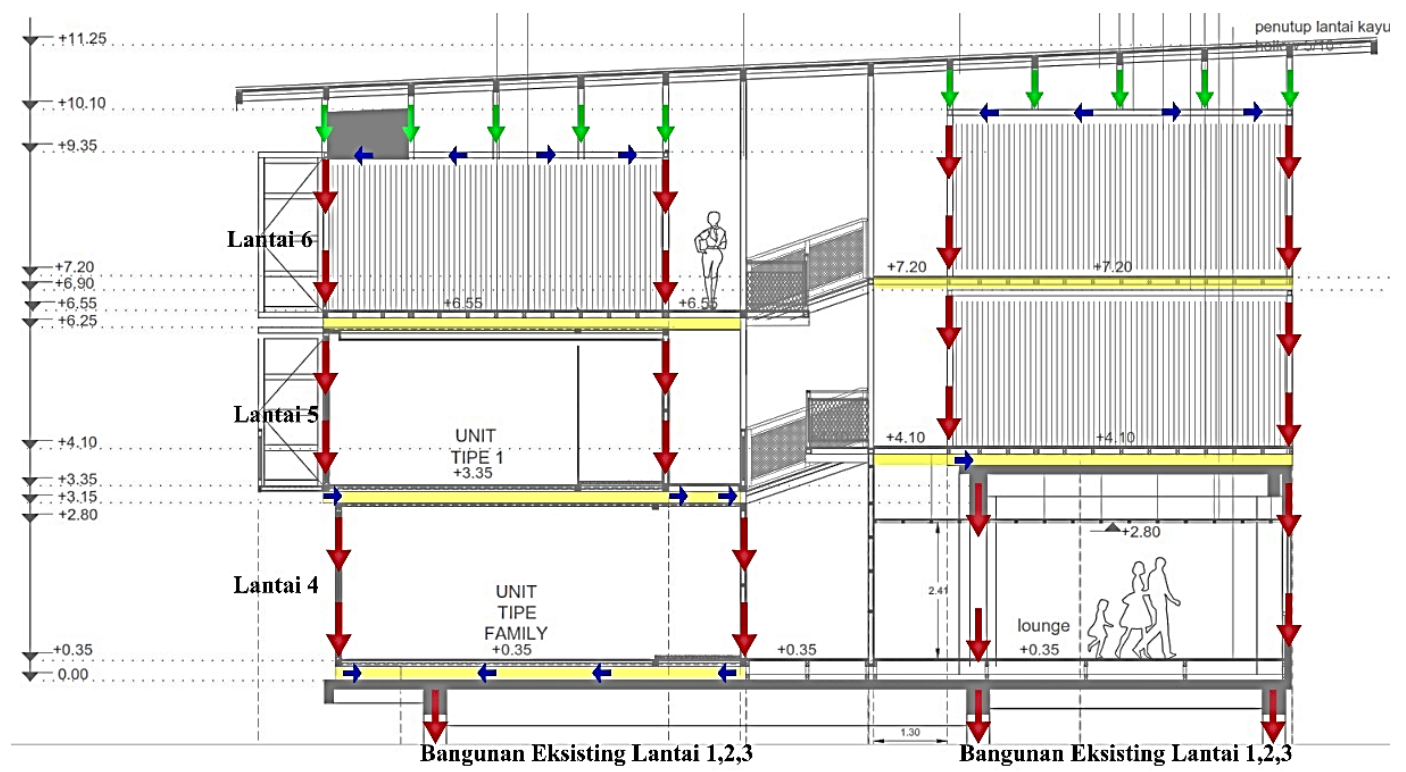

Keterangan gambar:

Warna kuning = baja iwf

Panah merah $=$ beban aksial
Panah hijau $=$ beban penutup atap

Panah biru $=$ beban lateral

Figur 14. Penyaluran beban IWF 
Pada kamar tidur terdapat penambahan elemen non struktural dengan tujuan untuk menunjang fungsi di dalamnya yaitu sebagai pembatas antara kamar dengan kamar dan pembatas antara kamar tidur dengan kamar mandi. Elemen non struktural itu adalah dinding partisi dengan material gypsum $9 \mathrm{~mm}+$ baja hollow 4/8.

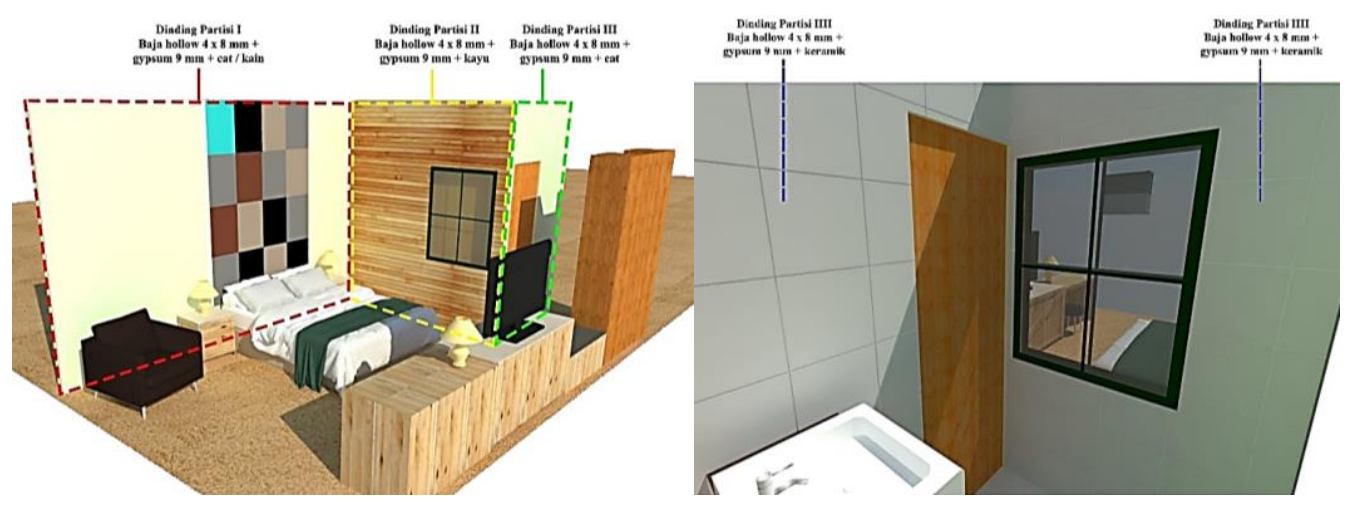

Figur 15. Dinding partisi kamar tidur dan kamar mandi

\subsubsection{STRUKTUR RANGKA KAKU}

Koridor memakai struktur rangka kaku dengan material baja. Penyaluran beban koridor terbagi dua yaitu penyaluran beban pada kolom koridor dan setengahnya lagi pada baja IWF di bawah kontainer. Sambungan antar balok baja IWF adalah jepit dengan plat baja dan baut.
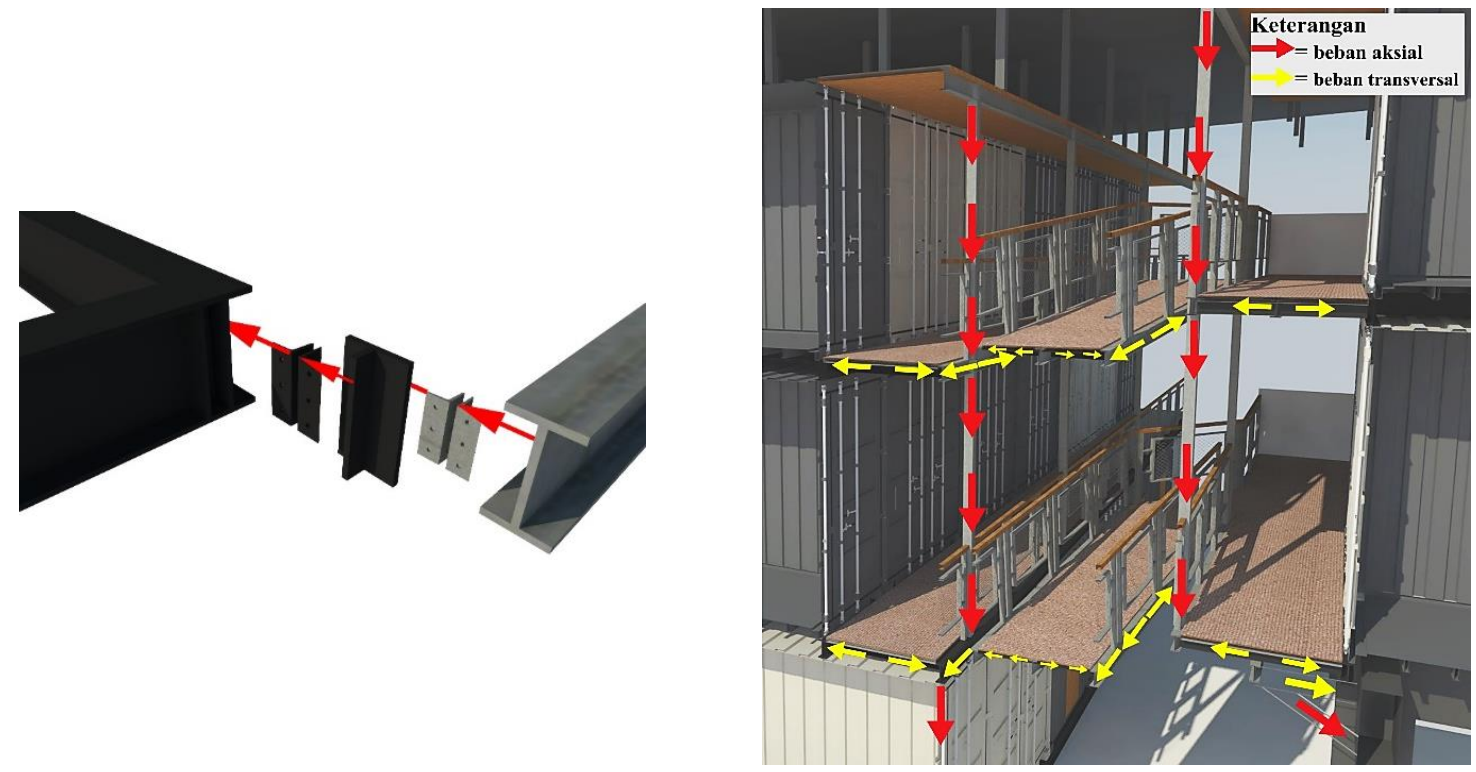

Figur 16. Sambungan baja pada koridor

Figur 17. Penyaluran beban koridor

Elemen struktural pada koridor adalah kolom baja hollow, balok baja hollow dan balok baja IWF 150. Elemen non struktural penunjang fungsi koridor adalah multiplek dan karpet. 


\subsection{HUBUNGAN STRUKTUR KONTAINER DAN RANGKA KAKU DENGAN DIMENSI DAN FUNGSI RUANG KAMAR TIDUR DAN KORIDOR}

Berikut ini akan dianalisis mengenai hubungan struktur kontainer dengan dimensi dan fungsi ruang, hubungan struktur rangka kaku dengan dimensi dan fungsi ruang.

\section{a. Hubungan Struktur Kontainer dengan Dimensi dan Fungsi Ruang Kamar Tidur}

Tabel 2. Hubungan proporsi struktur kontainer dengan dimensi kamar tidur

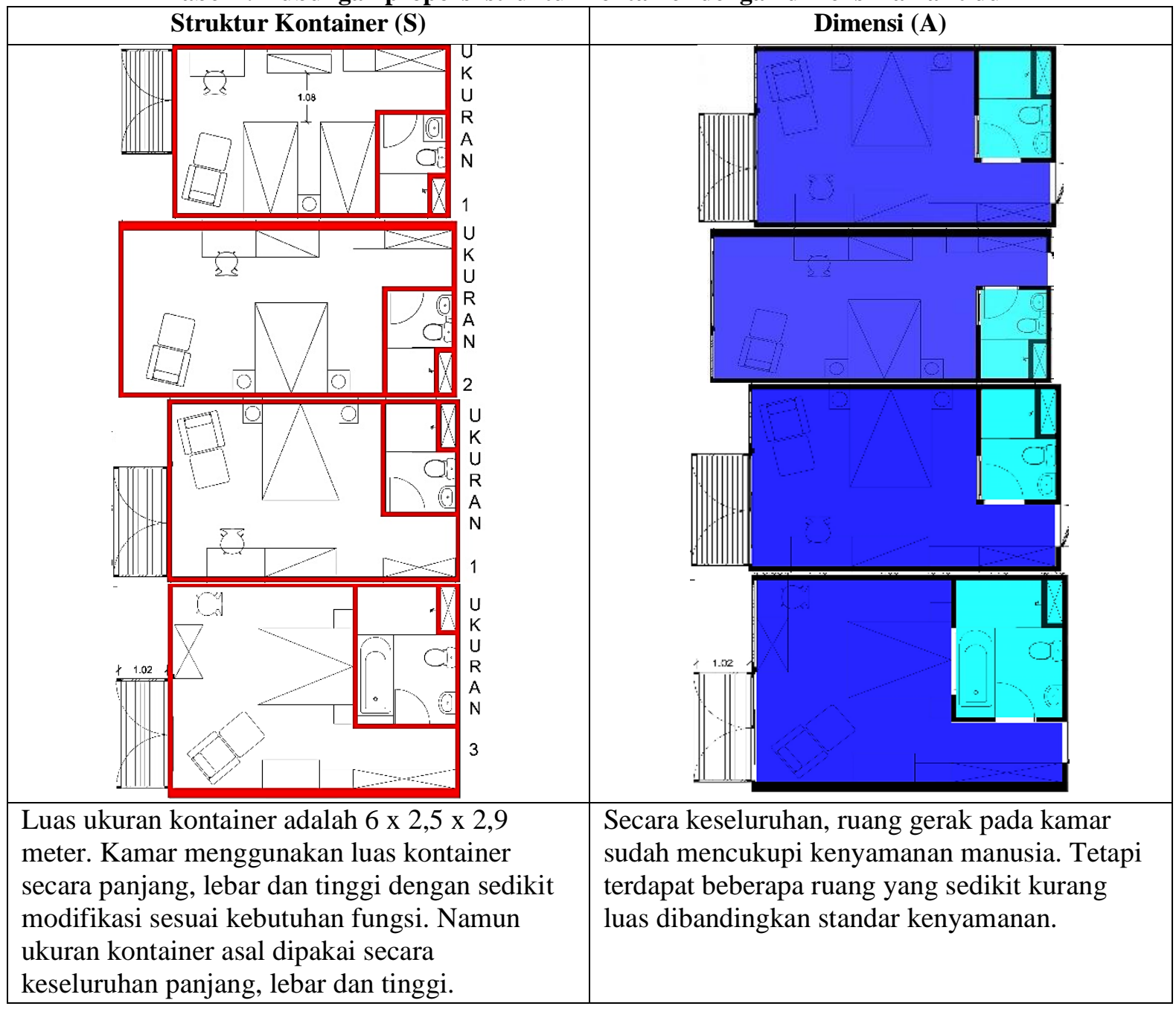

Tabel 3. Hubungan struktur kontainer dengan fungsi ruang kamar tidur 


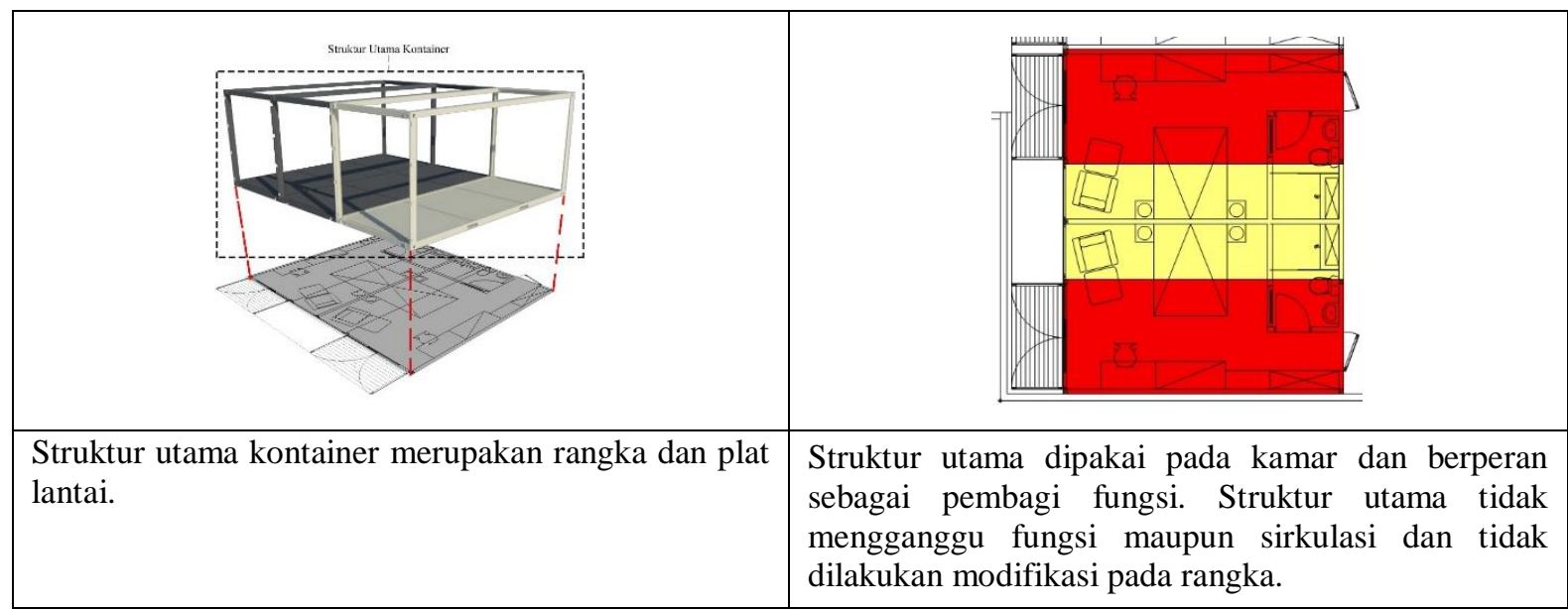

Kesimpulan hubungan struktur dengan dimensi adalah ukuran kontainer yang tetap secara panjang, lebar dan tinggi dapat dimanfaatkan sebagai fungsi kamar dengan penyesuaian antara lain yaitu penggabungan tiga kontainer menjadi dua kamar dan dua kontainer menjadi satu kamar. Perletakkan seperti tempat tidur, meja, bagian kamar mandi dan furniturnya diatur sedemikian rupa sehingga tercipta ruang kamar tidur yang nyaman. Hubungan struktur dengan fungsi ruang adalah rangka kontainer diletakkan pada sisi-sisi kamar sehingga tidak mengganggu fungsi maupun sirkulasi.

Jika hubungan struktur dan arsitektur (dimensi dan fungsi ruang) dikategorikan menurut teori Charleson (2005) dan Macdonald (2001), maka struktur kontainer dan ruang kamar tidur termasuk struktur bingkai dan struktur sebagai arsitektur. Dikatakan struktur bingkai karena struktur kontainer menggambarkan realisasi dan potensi pada bentuk arsitektur. Struktur kontainer dapat dikategorikan dalam struktur sebagai arsitektur karena struktur kontainer merupakan struktur 'murni'. Struktur kontainer diekspos dan diperlihatkan sebagai apresiasi arsitektur. Struktur kontainer diperlihatkan sebagai struktur dan arsitektur tanpa ditutup-tutupi. Dengan menggunakan ukuran kontainer yang tetap, proporsi yang dihasilkan tetap baik.

\section{b. Hubungan Struktur Rangka Kaku dengan Proporsi dan Fungsi Ruang Koridor}

Tabel 4. Hubungan proporsi struktur rangka kaku dengan dimensi koridor

\begin{tabular}{|c|c|}
\hline Struktur Rangka Kaku (S) & Dimensi (A) \\
\hline
\end{tabular}


Proporsi tinggi koridor adalah setinggi kontainer dan tidak diubah. Lebar koridor mengikuti kemampuan kontainer menggantung (kantilever) ke arah luar dengan bantuan baja IWF 200 untuk memberikan ruang koridor. Panjang koridor mengikuti panjang total lebar kamar hotel.
Ketinggian lantai ke plafon dan kemiringan ramp sudah sesuai dengan standar. Tetapi lebar dan luas koridor per kamar kurang dari standar di semua bagian koridor.

Hubungan struktur rangka kaku dengan dimensi koridor pada ukuran tinggi dan panjang koridor adalah memenuhi standar kenyamanan manusia. Namun pada lebar koridor, lebarnya kurang mencukupi standar kenyamanan manusia. Maka sarannya adalah lebar kontainer diperbesar agar mencapai standar minimum ruang gerak manusia demi kenyamanan beraktvitas.

Tabel 5. Hubungan struktur rangka kaku dengan fungsi ruang koridor

\begin{tabular}{|l|l|}
\hline \multicolumn{1}{|c|}{ Struktur Rangka Kaku (S) } & \multicolumn{1}{|c|}{ Fungsi Ruang (A) } \\
\hline $\begin{array}{l}\text { Struktur rangka kaku pada sisi kanan koridor } \\
\text { tidak mengalami perubahan. }\end{array}$ & $\begin{array}{l}\text { Struktur ruang berada di sisi kanan dan kiri } \\
\text { koridor sehingga tidak mengganggu ruang dan } \\
\text { sirkulasi. Sehingga struktur rangka kaku } \\
\text { termasuk struktur yang membagi ruang. }\end{array}$ \\
\hline
\end{tabular}

Kesimpulan hubungan struktur dengan arsitektur dalam hal proporsi dan fungsi ruang, dapat terlihat bahwa proporsi koridor tidak memenuhi standar kenyamanan dari lebar koridor. Tinggi koridor yang merupakan tinggi kontainer memenuhi standar kenyamanan, namun lebarnya tidak dikarenakan lebar koridor didapat dari seberapa jauh kontainer dapat bergeser ke arah luar dan memberi jarak untuk koridor. Struktur rangka kaku dapat dikategorikan dalam struktur sebagai pembuat bentuk karena bentuk koridor terbentuk dari bentuk struktur rangka kaku. Struktur rangka kaku terlihat, struktur berkontribusi secara langsung.

Jika hubungan struktur dengan arsitektur (dimensi dan fungsi ruang) dikelompokkan menurut teori Charleson (2005) dan Macdonald (2001), maka struktur rangka kaku dan besaran ruang kamar tidur termasuk dinding, struktur yang diterima karena struktur rangka kaku menentukan interior serta bentuk koridor diadopsi dari struktur yang masuk akal. Hubungan struktur rangka kaku dengan fungsi ruang adalah baik, sehingga termasuk struktur bingkai dan struktur sebagai arsitektur karena struktur rangka kaku menggambarkan realisasi dan mensintesiskan bentuk arsitektur serta bentuk struktur rangka kaku diperlihatkan apa adanya.

\subsection{Hubungan Struktur Kontainer dan Rangka Kaku dengan Permukaan Sisi-sisi Kamar Tidur dan Koridor}

Permukaan sisi-sisi yang akan dinilai adalah dilihat dari warna, pola dan tekstur awal, apakah berubah atau tidak. Dengan perubahan atau tidak, apakah kesan yang ditimbulkan cocok dengan fungsi atau tidak. Penilaian hubungan struktur dengan arsitektur kamar dan koridor akan digunakan parameter dalam tabel 2.

\section{a. Hubungan Struktur Kontainer dengan Permukaan Sisi-sisi Kamar Tidur}

Tabel 6. Hubungan warna struktur kontainer dengan warna kamar tidur

\begin{tabular}{|l|l} 
Warna Struktur Kontainer (S) & Warna Ruang Dalam Kamar Tidur (A) \\
\hline
\end{tabular}




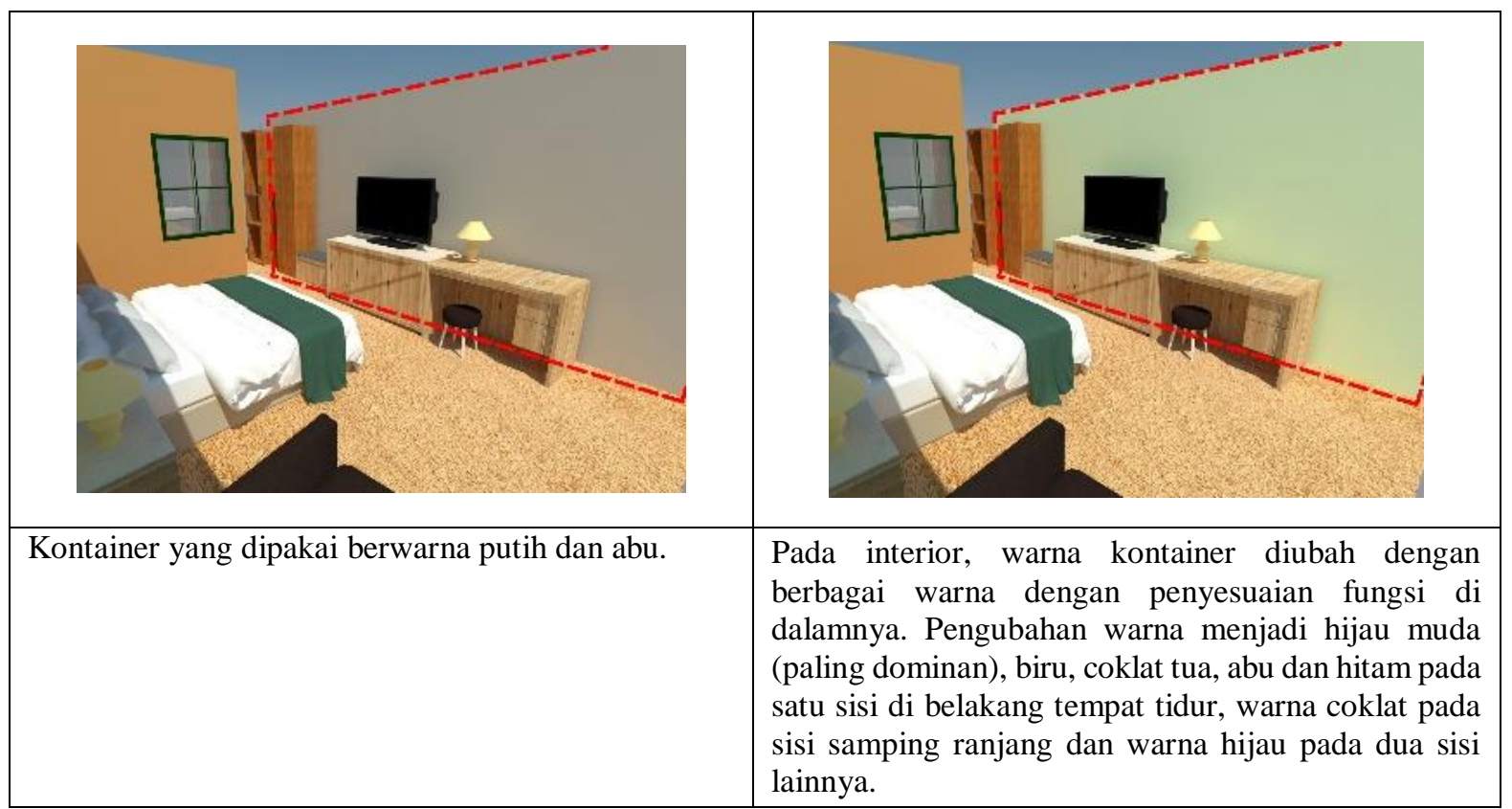

Perubahan warna dari warna asal kontainer adalah abu dan putih menjadi warna hijau muda, biru, coklat tua, abu, dan hitam dirasa kurang cocok pada kamar hotel karena terdapat beberapa warna seperti abu dan hitam yang menimbulkan kesan dingin, tidak ceria, dan membosankan. Sedangkan kamar tidur membutuhkan kesan hangat dan menenangkan (tetapi tidak membosankan).

Tabel 7. Hubungan pola struktur kontainer dengan pola kamar tidur

\begin{tabular}{|l|l|}
\hline Pola Struktur Kontainer (S) & Pola Ruang Dalam Kamar Tidur (A) \\
\hline $\begin{array}{l}\text { Kontainer memiliki pola yaitu garis vertikal lurus } \\
\text { yang cukup kuat dan tegas. Banyak terdapat garis } \\
\text { vertikal lurus pada dinding asli kontainer. Namun } \\
\text { dalam kamar pola vertikal lurus kontainer hilang dan } \\
\text { digantikan oleh material lain dengan beberapa pola } \\
\text { seperti, horisontal lurus, vertikal lurus dan polos. }\end{array}$ & $\begin{array}{l}\text { Pola pelingkup ruang kamar memberikan kesan } \\
\text { ilusi dari ketinggian. }\end{array}$ \\
\hline
\end{tabular}

Perubahan pola struktur kontainer yang dihasilkan, terdapat beberapa kesan yang kurang cocok untuk kamar seperti kesan lapang dan ilusi dari ketinggian. Kamar tidur tidak membutuhkan kesan lapang dan ilusi dari ketinggian karena kegiatan yang ada di dalam kamar bukan merupakan kegiatan aktif seperti di lapangan. 
Tabel 8. Hubungan tektur struktur kontainer dengan tekstur kamar tidur

\begin{tabular}{|l|l|l|}
\hline Tektur Struktur Kontainer (S) & Tekstur Ruang Dalam Kamar Tidur (A) \\
\hline $\begin{array}{l}\text { Kontainer memiliki dinding yang unik yaitu seng } \\
\text { gelombang. Seng gelombang memiliki tekstur yang } \\
\text { bergelombang jengan jarak masing-masing } \\
\text { gelombang yang cukup dekat. }\end{array}$ & $\begin{array}{l}\text { Kesan yang ditimbulkan dari tekstur material di dalam } \\
\text { kamar tidur adalah indah, hangat, bersih dan rapi. }\end{array}$ \\
\hline
\end{tabular}

Dari hasil analisis, perubahan tektur kontainer yaitu seng gelombang menjadi dinding gypsum yang memiliki tektur halus menghasilkan kesan yang lebih cocok untuk kamar yaitu indah, hangat, bersih dan rapi.

Kesimpulan perubahan warna, pola dan tekstur struktur kontainer menjadi dinding gypsum, secara keseluruhan adalah kurang cocok dengan kamar. Karena perubahan warna dan pola menghasilkan kesan yang kurang cocok untuk kamar, tetapi perubahan tektur menghasilkan kesan yang cocok untuk kamar.

\section{b. Hubungan Struktur Kontainer dengan Permukaan Sisi-sisi Kamar Tidur}

Tabel 9. Hubungan warna struktur rangka kaku dengan warna ruang dalam kamar tidur

\begin{tabular}{|l|l|}
\hline \multicolumn{2}{|c|}{ Struktur Rangka Kaku (S) } \\
\hline
\end{tabular}


Setelah dianalisis, ternyata tidak terjadi perubahan warna dari material asal yaitu seperti penggunaan kayu tetap berwarna coklat, begitu pula dengan penggunaan besi tetap berwarna abu. Dari warna asal yang tidak mengalami perubahan warna, dihasilkan kesan yang cocok dengan fungsi koridor yaitu seperti kokoh, stabil, dan netral. Tetapi terdapat warna coklat pada plafon yang menimbulkan kesan berat dan menekan dengan tujuan agar tinggi lantai koridor ke plafon yang cukup tinggi tidak terlalu terasa tinggi.

Tabel 10. Hubungan pola struktur rangka kaku dengan pola ruang dalam kamar tidur

\begin{tabular}{|l|l|}
\hline Struktur Rangka Kaku (S) & Pola (A) \\
\hline & $\begin{array}{l}\text { Kesan yang tercipta dari pola material pada koridor } \\
\text { adalah lapang, leluasa, relaksasi, lebar, pemaksaan, } \\
\text { kekuatan dan menciptakan atmosfer yang agung. } \\
\text { Kesan ini cocok untuk koridor sebagai ruang semi } \\
\text { publik. }\end{array}$ \\
mengalami modifikasi sehingga pola asal yang \\
terlihat.
\end{tabular}

Dari analisis didapatkan bahwa pola asal tetap dipertahankan dan dapat menghasilkan kesan yang cocok bagi koridor yaitu memberikan kesan lapang, leluasa dan lebar.

Tabel 11. Hubungan tekstur struktur rangka kaku dengan tektur ruang dalam kamar tidur

Struktur Rangka Kaku (S)


Tekstur dari material kayu, baja, kontainer dan karpet tetap dipertahankan tanpa dimodifikasi
Tekstur koridor menciptakan suasana hangat, lapang dan leluasa, alami, bersih dan sederhana, tetapi terdapat kesan pemaksaan dan kekuatan yang dirasa kurang cocok untuk koridor. Secara keseluruhan, tekstur ini cocok untuk di koridor.

Tekstur asal tidak mengalami perubahan, tetapi dengan mempertahankan tekstur kesan yang dihasilkan tetap baik dan cocok dengan fungsi koridor. Kesan yang dihasilkan adalah hangat, lapang dan leluasa, alami, bersih, dan sederhana cocok untuk koridor.

Kesimpulan hubungan struktur rangka kaku dengan permukaan sisi-sisi ruang dalam koridor secara keseluruhan adalah cocok dengan fungsi koridor. Terdapat beberapa kesan yang dirasa kurang cocok dan memerlukan sedikit perbaikan.

\section{KESIMPULAN DAN REKOMENDASI}

Berikut ini adalah kesimpulan dari analisis diatas. Rekomendasi akan dijabarkan mengenai hal-hal yang dirasa kurang benar dan cocok pada ruang kamar tidur dan kamar mandi.

\subsection{KESIMPULAN STRUKTUR KONTAINER DAN STRUKTUR RANGKA KAKU PADA KAMAR DAN KORIDOR}

Setelah dianalisis, ternyata fungsi utama penambahan baja IWF 200 yang berada di bawah kontainer merupakan struktur bagi koridor. Baja IWF 200 juga berfungsi untuk menyalurkan beban pada kontainer yang posisinya tidak berada tepat sama dengan kontainer dibawahnya. Dengan adanya baja IWF 200, maka koridor tidak memerlukan kolom pada salah satu sisinya. Modifikasi kontainer maju-mundur dapat dicapai karena terdapat baja IWF 200 sebagai balok penyalur beban.

Modifikasi maju-mundur kontainer memiliki tujuan lain yaitu untuk memberikan ruang bagi koridor. Dengan begitu, koridor kiri lantai lima tidak memerlukan kolom dibawahnya dan beban dapat langsung disalurkan ke kontainer di bawahnya.

\subsection{KESIMPULAN HUBUNGAN STRUKTUR KONTAINER DAN RANGKA KAKU DENGAN RUANG KAMAR TIDUR DAN KORIDOR}

Struktur utama kontainer yang dimanfaatkan seluruhnya secara dimensi keseluruhan menghasilkan proporsi yang baik bagi kamar. Sedangkan koridor dengan struktur rangka kaku tetapi ukuran tinggi dan lebar terpengaruh dengan ukuran tinggi dan lebar kontainer menghasilkan proporsi yang kurang nyaman bagi pengguna. Struktur kontainer dan rangka kaku sama-sama merupakan struktur sebagai pembagi ruang.

\subsection{KESIMPULAN HUBUNGAN STRUKTUR KONTAINER DAN RANGKA KAKU DENGAN KUALITAS RUANG KAMAR TIDUR DAN KORIDOR}

Suasana dan kesan yang timbul pada koridor sudah cocok dengan fungsi koridor. Namun pada saat memasuki kamar hotel, dirasa masih ada beberapa warna, tekstur dan pola yang kurang cocok untuk ditempatkan di dalam kamar.

Hubungan struktur dengan arsitektur kamar dari segi permukaan sisi yaitu warna, pola dan tektur perlu diperbaiki dari material pelingkup kamar agar menciptakan suasana yang cocok untuk kamar hotel. Hubungan struktur dengan arsitektur koridor dapat dinilai baik karena penggunaan material asal yang tidak diubah dan menghasilkan kesan yang cocok bagi koridor. 


\subsection{REKOMENDASI}

Demi tercapainya kualitas serta kenyamanan gerak dibutuhkan beberapa penyesuaian dan perubahan seperlunya. Terdapat beberapa kesan yang diberikan dari warna, pola, tekstur yang kurang cocok untuk di dalam kamar.

Kesan warna yang kurang cocok adalah pemakaian banyak warna hitam, abu yang menimbulkan kesan dingin, jauh, tidak ceria, seperti di penjara dan membosankan. Pemakaian warna tersebut dikurangi sehingga tidak mendominasi. Warna coklat plafon yang dirasa kurang cocok untuk koridor karena memberikan efek menekan dan berat.

Pola yang kurang cocok bagi kamar tidur adalah vertikal lurus yang memberi kesan pemaksaan, kekuatan serta menciptakan atmosfer yang agung dan memberikan ilusi dari ketinggian ruang. Pola vertikal lurus tercipta dari susunan kotak-kotak kain dari ranjang hingga plafon. Penempatan kotak-kotak kain tidak harus sampai plafon agar tidak menunjukkan kesan vertikal lurus. Tekstur yang kurang cocok untuk koridor adalah tekstur kontainer yang mengekspresikan pemaksaan dan kekuatan.

Ukuran lebar pada ruang depan kamar mandi dan ruang gerak bagi kamar mandi dan kloset rata-rata di semua kamar kurang dari standar kenyamanan gerak. Ukuran lebar koridor haruslah diperlebar agar tercapai kenyamanan ruang gerak.

\section{DAFTAR PUSTAKA}

\section{Buku:}

Charleson, Andrew W. (2005).Structure as Architecture.Oxford:Architectural Press.

Ching, D. K. 2000. Bentuk, Ruang, Tatanan.Cetakan I.Terjemanah: Nurahma Tresani H, Ir. Jakarta: Erlangga.

Heins, Matthew.2016.The Globalization of American Infrastructure.United Kingdom: Routledge 1 edition. Hendraningsih, dkk. 1985. Peran, Kesan, dan Pesan Bentuk-Bentuk Arsitektur. Jakarta: PT. Penerbit Djambatan.

Hindarto, Probo.(2015).3 Dekade Karya Desain Arsitektur Inspiratif.Jakarta : Griya Kreasi (Penebar Swadaya Grup)

International Chamber of Shipping.(2008).Sea Transport of Containers by Sea.American : Marisec Publications

Macdonald, Angus J.(2001).Structure and Architecture.Oxford: Butterworth-Heinemann.

Mahnke, F.H.(1996). Colour, Environment, and Human Response. New York: Wiley \& Sons.

Neufert, Ernst.(1996). Data Arsitek Jilid 1 ed ; 3. Jakarta : Erlangga

Schodek, Daniel L. (1999).Struktur.Edisi kedua. Jakarta: Erlangga.

Suptandar, J.Pamudji.(1991).Desain Interior : Pengantar Merencana Interior untuk Mahasiswa Desain dan Arsitektur. Jakarta: Djambatan

\section{Tesis:}

Rachmad, Paulus Sukarjono.2011.Model Rusunami Peti Kems Pada Daerah Pesisir Kota Semarang = Model of Rusunami Container in The Coastal of Semarang City. Bandung : UNPAR

\section{Internet:}

Arthanugraha.com. (2016, 22 Desember). Mengenal Peti Kemas / Kontainer Refenrensi Logistik Indonesia. Diperoleh 9 Oktober 2017, dari http://www.arthanugraha.com/mengenal-peti-kemas-kontainer/

BGR Intergrated Logistics Solution. Depo Container and Handling. Diperoleh 21 Oktober 2017, dari http://www.bgrindonesia.com/subpage.php?page=services\&menudetail=bgr warehousing \&sub=11

gCaptain (2016, 24 Mei). IMO Urges 'Pragmatic' Approach for Launch of New Container VGM Rules. Diperoleh 21 Oktober 2017, dari http://gcaptain.com/imo-urges-pragmatic-approach-for-launch-ofnew-container-vgm-rules/ 
Merdeka.com (2012,23 Oktober). Bisnis unik jasa penitipan kontainer di Cilincing. Diperoleh 21 Oktober 2017, dari https://www.merdeka.com/politik/bisnis-unik-jasa-penitipan-kontainer-di-cilincing.html

Property and the City. (2016, 30 Mei). Property Trend. Diperoleh 6 Oktober 2017, dari http://www.propertyandthecity.com/index.php/property-trend-list/635-properti-dari-kontainer

Wikipedia Ensiklopedia Bebas. Peti Kemas. Diperoleh 9 Oktober 2017, dari https://id.wikipedia.org/wiki/Peti kemas 